\title{
Is Eminectomy Effective in the Management of Chronic Closed Lock?
}

\author{
Ketan Shah ${ }^{1}$ Andrew Nicholas Brown ${ }^{2}$. Robert Clark $^{3}$ (D) Mohammed Israr $^{4}$. \\ Donald Starr ${ }^{2}$. Leo F. A. Stassen ${ }^{4}$
}

Received: 11 July 2018/Accepted: 18 March 2019/Published online: 5 April 2019

(C) The Author(s) 2019

\begin{abstract}
Purpose This study assesses the effectiveness of eminectomy in the management of chronic closed lock, refractory to conservative medical management in the largest multicentred study of its kind in the UK, with a cohort of 167 patients. Temporomandibular mandibular joint disorder affects $30 \%$ of adults in the UK. Chronic closed lock is a well-documented sub-type.

Method A retrospective study of patients with refractory closed lock was carried out, where conservative management had been implemented for a minimum of 6 months. Refractory patients were offered eminectomy at three separate centres over a period from 1995 to 2011. The primary variable was the inter-incisal distance (IID). Other variables included pain, clicking and nerve damage preand post-operatively.

Results There were 167 patients across all three centres, $81 \%$ of which were female. The mean IID was $23 \mathrm{~mm}$ preoperatively and $37 \mathrm{~mm}$ post-operatively. There was a statistically significant association with the primary predictor variable, yielding a $p$ value of $<0.05$. Clicking resolved completely post-operatively in 84 patients (58\%). Pain subjectively improved in $56 \%$ cases.

Conclusion Eminectomy is a safe and effective surgical procedure and has a role to play as a second-line surgical
\end{abstract}

Robert Clark

rc15804@bristol.ac.uk

1 Morriston Hospital, Swansea, UK

2 Hull Royal Infirmary, Hull, UK

3 Department of Oral and Maxillofacial Surgery, University Hospital Bristol, Bristol Royal Infirmary, Upper Maudlin Street, Bristol BS2 8HW, UK

4 St. James's Hospital, Dublin, Ireland option in the management of closed lock after more conservative medical options have failed.

Keywords Temporomandibular joint .

Temporomandibular joint dysfunction - Closed lock . Eminectomy

\section{Introduction}

Temporomandibular joint disorder (TMD) is a collective term for a range of different clinical problems that encompass the muscles of mastication, the temporomandibular joint (TMJ) and the associated structures $[1,2]$. It is estimated that $20-30 \%$ of adults $[2,3]$ will experience the symptoms of TMD. The aetiology of TMD remains unknown but is thought to include parafunctional activity, stress, previous trauma and internal derangement of the disc complex [2].

Closed lock is a specific type of TMD where there is derangement of the articular disc complex and refers to the displacement of the disc, most commonly anteromedially, without reduction and resultant limited mouth opening [4].

In a normal joint, on initial mouth opening, the condylar head rotates followed by translation along the articular eminence on further opening. The articular disc will translate with the condyle to remain interpositioned between the head and the eminence. In patients with closed lock, the translation of the condyle is limited by the failure of the meniscus to reduce, as a consequence of the disc being displaced, most commonly anteromedially, with the posterior band becoming trapped anterior to the condyle [5]. It has been postulated that the articular disc may be attached to the eminence via adhesions, preventing reduction and has been linked with osteoarthrosis [6]. 
Closed lock can be described as being acute or chronic depending on the duration of locking [4] and is frequently accompanied with characteristic symptoms including: significant jaw pain, limitations of jaw movement (namely reduced maximal opening) and functional impairment (eating) [7]. However, a number of patients with anteromedial meniscus displacement report no clinic symptoms $[8,9]$ indicating that other factors are influential to the aetiology and severity of closed lock [9]. These factors include the depth of the glenoid fossa, the steepness of the eminence and the size of the condylar head [8].

The treatment modalities for closed lock are well documented within the literature and include both medical and surgical management options. Medical management includes the use of non-steroidal anti-inflammatories, steroid therapy, rehabilitation with orthotic devices, physical therapy and cognitive behavioural therapy [7]. The minimally invasive surgical options including arthroscopy and arthrocentesis are considered as first-line surgical modalities, with open surgery including: condylar shave, plication procedures and eminectomy of the articular eminence as alternative, secondary surgical procedures [7]. The consensus of the current literature is that surgical treatment for TMJ disc displacement without reduction, including that of closed lock, should be deferred for a minimum of 6 months to allow sufficient time for comprehensive medical management and rehabilitation [4, 7]. Closed lock that proves refractory to non-surgical interventions should then be considered for an interventional surgical approach. In this retrospective study, the rationale for eminectomy as a surgical treatment option for closed lock is the removal of the articular eminence, which thereby eliminates the anatomic structure against which the articular disc becomes trapped on mouth opening and thereby relieves some or all of the symptoms. It has been hypothesised that articular eminectomy may successfully treat patients suffering closed lock and was first described by Stassen and Currie in 1994 [8]. The pilot study concluded that 'Eminectomy appears to be a safe and simple method of reducing a closed lock of the TMJ' [8].

Eminectomy as a standard surgical procedure was carried out by a preauricular incision using the Al-Qayat Bramley approach to expose the articular eminence followed by adequate removal and recontouring of the articular eminence using a bone saw [10]. This procedure helps to eliminate mechanical interference and facilitates a smooth functioning surface for the joint translation. Unlike some open TMJ surgical procedures, the procedure is intracapsular and the disc is not surgically repositioned and there is no interference with the internal joint mechanism [5]. The surgical treatment has a potential risk of damage to the temporal and zygomatic branches of the facial nerve. The literature reports varying degrees of incidence, from 9 to $18 \%$ of patients reporting transient weakness of facial nerve post-operatively [4]. The success of the operation can be measured by the following criteria: reduction in pain, improvement in function (mouth opening) and reduction in clicking.

This study aims to assess the effectiveness and role of eminectomy as an alternative surgical option for the management of chronic closed lock.

\section{Materials and Methodology}

Due to the retrospective nature of this study, it was granted an exemption in writing by the University of Leeds IRB.

In this retrospective study, data were collected from three different 'Oral and Maxillofacial Departments': Sunderland Royal Infirmary (UK), Hull Royal Infirmary (UK) and St James' hospital Dublin (Ireland), between the years of 1995 and 2011. All patients who had undergone eminectomy were identified using the operating theatre lists, and the subsequent patient records were requested and analysed. Eminectomies performed only as a treatment for closed lock were included, whilst cases where it had been used for recurrent dislocation were excluded from the study. There were no other exclusion criteria.

The primary outcome variable is the inter-incisal distance at the point of discharge from the clinic at a minimum of 6 months post-operatively. The other outcome variables include pain and clicking improvement at a minimum of 6 months post-operatively.

Wilkes score and visual analogue scores were not recorded for all patients in this retrospective study, and therefore a customised proforma was constructed to facilitate data collection and analysis (Table 1). Using the patients' medical records, the proforma was completed recording the patient demographics, gender, pre-operative and post-operative symptoms including pain, mouth opening and clicking and any other documented surgical complications.

\section{Results}

Between 1995 and 2011, 167 patients underwent eminectomy for closed lock. The distribution between the three units and gender distribution is shown in Table 2.

Of these patients, 111 underwent a unilateral eminectomy with 56 undergoing a bilateral eminectomy. The mean duration from the onset of symptoms until the initial secondary care consultation was 25 months (range 6 months-20 years) with all patients proving refractory to conservative management, e.g. bite-raising appliances, splints and medications. A total of 102 patients (61\%) reported a history of bruxism, mandibular trauma or 
Table 1 Clinical proforma used in data collection

\begin{tabular}{|c|c|c|}
\hline \multicolumn{2}{|l|}{ Age } & _ years \\
\hline \multicolumn{2}{|l|}{ Gender } & $M / F$ \\
\hline Pre-operation & $\begin{array}{l}\text { Mouth opening } \\
\text { Function } \\
\text { Pain } \\
\text { Clicking }\end{array}$ & $\begin{array}{l}\text { - } m m \\
\text { eg. Ability to masticate } \\
\text { Mild / mod / severe } \\
Y / N\end{array}$ \\
\hline \multicolumn{2}{|c|}{ Duration of symptoms } & _ months_years \\
\hline \multicolumn{2}{|c|}{$\begin{array}{l}\text { Exacerbating factors? } \\
\text { Bruxism, trauma, nail-biting etc }\end{array}$} & \\
\hline \multicolumn{2}{|c|}{ Indication for eminectomy } & $\begin{array}{l}\text { Recurrent dislocation } \\
\text { Closed lock }\end{array}$ \\
\hline \multicolumn{2}{|c|}{$\begin{array}{l}\text { Treatment attempted before operation } \\
\text { eg soft BRA }\end{array}$} & \\
\hline \multicolumn{2}{|l|}{ MRI report: } & \\
\hline \multicolumn{2}{|c|}{ Details of eminectomy: } & Right / Left / Bilateral \\
\hline \multicolumn{2}{|c|}{ Length of hospital stay: } & _ nights \\
\hline $1^{\text {st }}$ post op $r / v$ : & $\begin{array}{l}\text { Mouth opening } \\
\text { Function } \\
\text { Pain } \\
\text { Clicking }\end{array}$ & $\begin{array}{l}\text { Eg. Ability to masticate } \\
\text { Mild / mod / severe } \\
Y / N\end{array}$ \\
\hline On discharge: & $\begin{array}{l}\text { Mouth opening } \\
\text { Function } \\
\text { Pain } \\
\text { Clicking }\end{array}$ & $\begin{array}{l}\text { Eg. Ability to masticate } \\
\text { Mild/mod/ severe } \\
Y / N\end{array}$ \\
\hline \multicolumn{2}{|l|}{ Complications: } & $\begin{array}{l}\text { Facial nerve weakness - perm / temp } \\
\text { Auriculotemporal - perm / temp } \\
\text { Great auricular-perm / temp }\end{array}$ \\
\hline \multicolumn{2}{|l|}{ Progression: } & $\begin{array}{l}\text { Discharge } \\
\text { Continued follow-up } \\
\text { Further operative intervention } \\
\text { Other }\end{array}$ \\
\hline
\end{tabular}

parafunctional habit, e.g. nail biting. The type and frequency of pre-op symptoms are recorded in Fig. 1. It shows most patients had combined symptoms of either pain and clicking or clicking with limited mouth opening.
It is pertinent to note that the majority of patients undergoing eminectomy across the three centres were between 20 and 40 years of age. The age distribution is demonstrated in Fig. 2. 
Table 2 Gender distribution

\begin{tabular}{lll}
\hline Hosp/sex & M & F \\
\hline SRH & 9 & 35 \\
HRI & 9 & 29 \\
Dublin & 13 & 72 \\
Total & 31 & 136 \\
Percentage distribution & $19 \%$ male & $81 \%$ Female \\
\hline
\end{tabular}

Looking at the three main symptoms of pain, clicking and limited mouth opening and comparing them to the preoperative symptoms, the results were as follows.

Pain subjectively improved in $56 \%$ cases and remained unchanged in $37 \%$ of the cases. It however worsened in $5 \%$ of the cohort. This is demonstrated in Fig. 3.

Clicking was present pre-operatively in 144 cases, 11 cases had no clicking, whilst in the remaining 12 cases the notes failed to record the symptom. Post-operatively, the clicking resolved in 84 patients $(58 \%)$ completely, whilst the remaining 60 cases $(42 \%)$ continued to have clicking after surgery. This is highlighted in Fig. 4.

In 159 out of 167 cases, it was possible to assess improvements in mouth opening, by comparing the interincisal distance (IID) pre-operatively and at discharge. The mean pre-operative IID was $23 \mathrm{~mm}$, whereas the mean IID at discharge was $37 \mathrm{~mm}$. This is exhibited in Fig. 5. Interincisal distance is the primary treatment outcome marker for determining the success of eminectomy as a surgical procedure for the correction of a closed lock. Table 3 highlights the pre-operative and post-operative IIDs across all three centres. The data in black represent the data from
Age ranges ( in years)

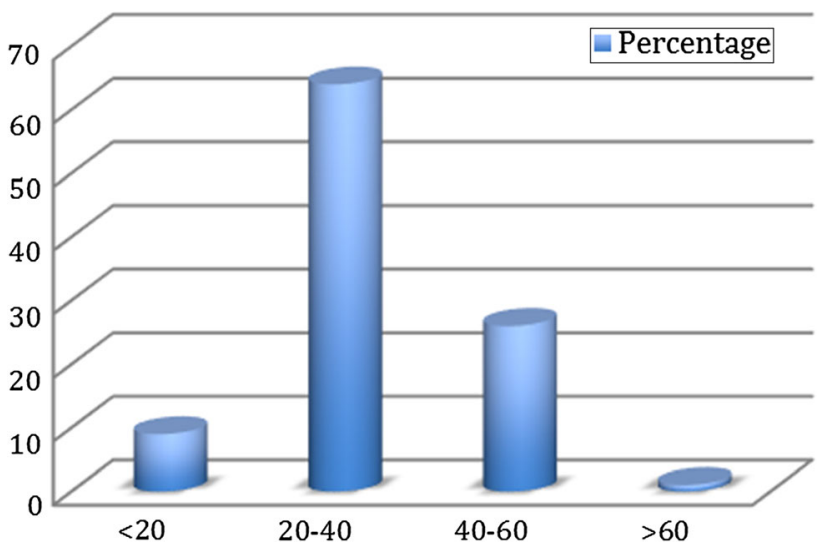

Fig. 2 Age distribution of the patient cohort

Dublin, those in red represent the data from Hull, and those in blue represent the data from Sunderland. A paired ' $t$ ' test was performed yielding a $p$ value of $<0.05$ showing that the improvement in the IID is statistically significant and the null hypothesis that 'eminectomy is ineffective for managing chronic closed lock' can be rejected.

The complications experienced by the patients included in the cohort were recorded in all three centres. Surgical complications with regards to facial nerve weakness were temporary in six cases $(4 \%)$, and permanent weakness was only found in three cases $(2 \%)$. Temporary paraesthesia in the region of the auriculotemporal nerve was seen in 15 cases $(9 \%)$, whilst three cases $(2 \%)$ demonstrated altered sensation over the distribution of the Greater Auricular nerve. Permanent paraesthesia was present in seven cases
Fig. 1 Type and frequency of pre-operative symptoms

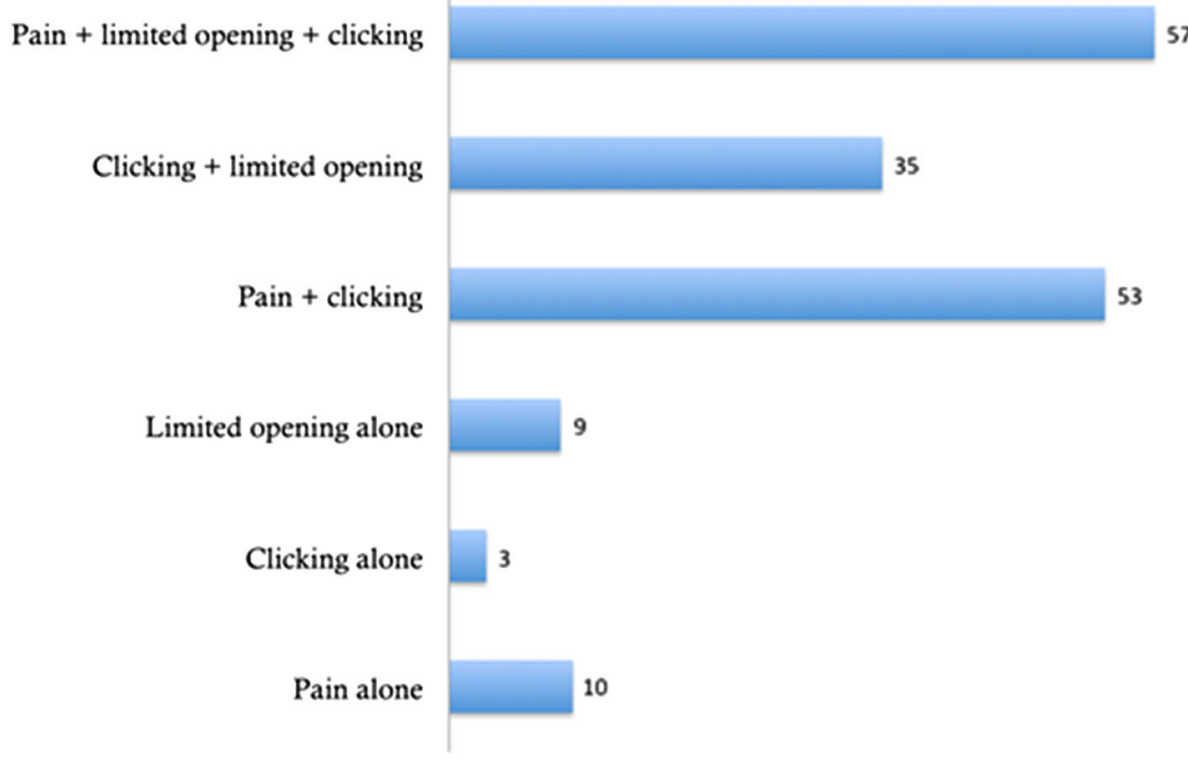


Fig. 3 Assessment of pain post-operatively

\section{Improvement of pain}

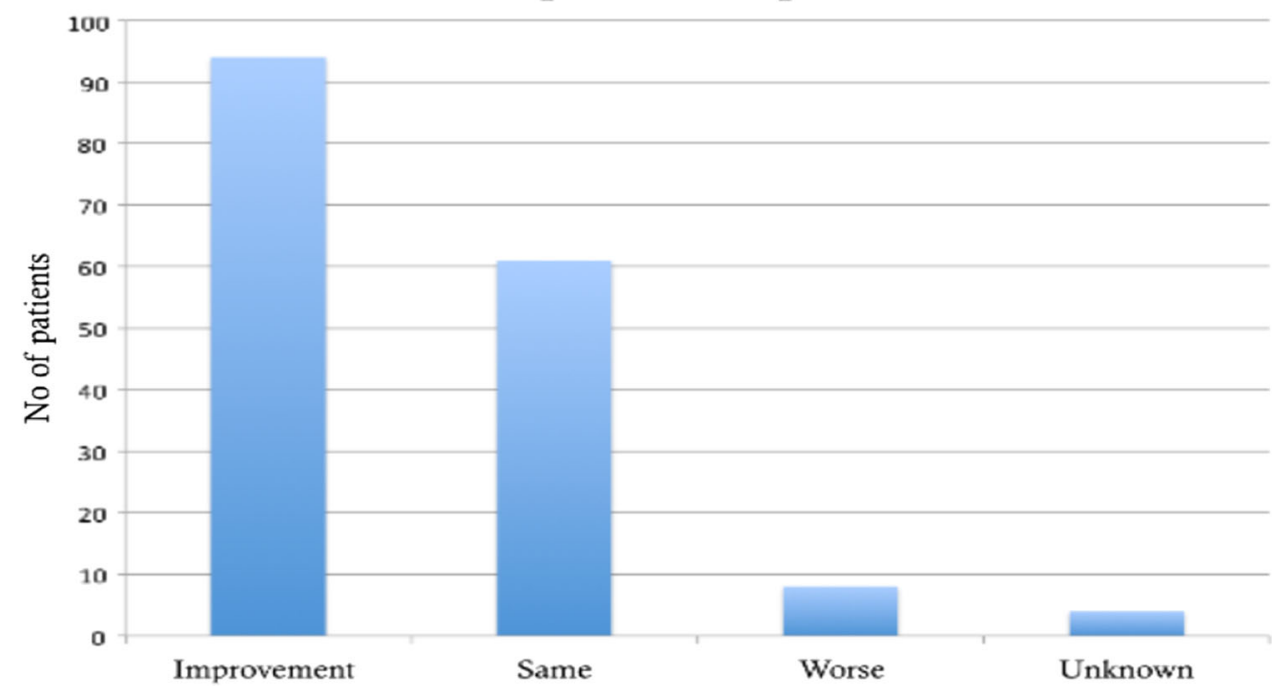

Clicking - pre-op vs post-op

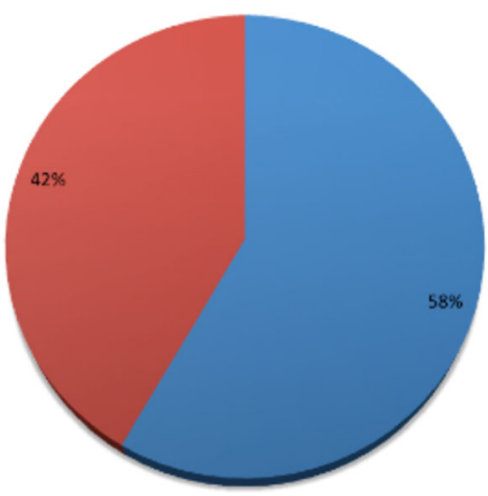

Resolution (84)

No resolution (60)

Fig. 4 Pre-operative and post-operative clicking

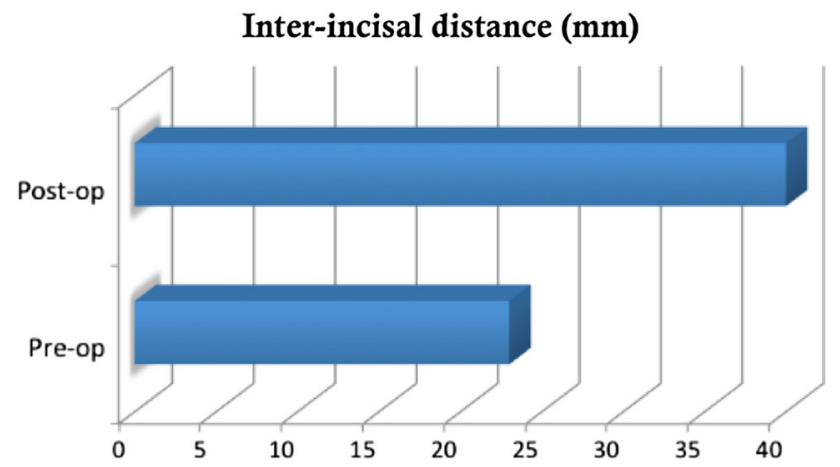

Fig. 5 Inter-incisal distance (IID) pre- and post-operatively

(4\%) over the distribution of the auriculotemporal nerve and two cases $(1 \%)$ over the greater auricular nerve distribution. Three patients developed wound infection that was resolved with an oral antibiotic regime. In total, 108 patients out of 164 were discharged with a mean follow-up of 12 months (Table 4).

Table 3 Pre- and post-operative inter-incisal distance data from all three centres

\begin{tabular}{lccll}
\hline & Hull & Dublin & Sunderland & Mean total \\
\hline Mean pre-op IID (mm) & 20.8 & 24.2 & 25.5 & 23 \\
Mean post-op IID (mm) & 37.7 & 33.9 & 38.3 & 37 \\
Mean improvement IID & 16.4 & 9.4 & 12.7 & 13 \\
\hline
\end{tabular}

Table 4 Post-operative complications

\begin{tabular}{ll}
\hline Complication & Percentage of occurrence $(\%)$ \\
\hline Facial nerve weakness & 4 \\
Temporary & 2 \\
Permanent & \\
Auriculotemporal nerve weakness & 9 \\
Temporary & 4 \\
Permanent & \\
Greater auricular nerve weakness & 2 \\
Temporary & 1 \\
Permanent & 2 \\
Wound infection &
\end{tabular}

\section{Discussion}

The management of closed lock initially involves conservative medical management. Failed conservative medical treatment is usually followed by TMJ arthrocentesis. The procedure has been shown in the literature to be minimally invasive yet very effective, relieving symptoms in more than $80 \%$ of cases [7]. However, in this retrospective study, 
eminectomy has been shown as a safe and effective method that can be considered as a second-line surgical treatment option.

Recent studies by Sidebottom et al. 2013 show that open temporomandibular surgeries can benefit patients with previous failed arthroscopy to help manage their pain, restriction and locking, especially in Wilkes stage 3 [11]. The paper also highlighted that patients with Wilkes stage 5 had a higher risk of deterioration and poorer outcome after open temporomandibular joint surgery, and this should be considered an important predictor and must be highlighted in their consent $[11,12]$.

Articular eminectomy has long been used for the treatment of recurrent articular disc dislocation by allowing free movement of the condyles through removal of the obstruction. In 1984, Hall demonstrated the use of meniscoplasty combined with a rudimental eminectomy for the treatment of closed lock, experiencing some degree of success [13]. In 1994, Nitzan and Dolwick [14] postulated on the basis of 194 operated cases that adhesions caused by increased synovial viscosity and/or a hydraulic vacuum effect on the disc causing it to press against the slope of eminence can be alleviated by eminectomy [14]. Stassen et al. in a pilot study discussed that the procedure is safe and simple to use for treatment of a closed lock [8]. Eminectomy results in removal of the barrier to articular disc activity and therefore decompresses the intra-capsular compartment and creates a larger anterior recess in the superior joint space [15]. The term eminectomy has also been rephrased as eminoplasty and essentially involves the mechanical release by removal and recontouring of the bony obstruction of the eminence. It thereby facilitates improved mouth opening and subsequent resolution of clinical symptoms [7]. It is essential to point out that the procedure of surgical eminectomy/eminoplasty must ensure good bony clearance medially and smooth contouring of the articular fossa to allow the smooth translation of the joint. It is also essential to point out that some patients with an anteriorly displaced disc may have no symptoms despite MRI findings, and this can sometimes be explained occasionally by slow, natural resorption of anterior surface of condylar head or posterior aspect of the articular eminence to create the space to release the trapped disc-natural eminoplasty.

The contraindications for eminectomy are widely discussed in the literature [16]. There are a number of relative contraindications including chronic mandibular dislocations associated with a shallow articular eminence and radiographic evidence of a vascularised eminence [16]. A single, absolute contraindication to eminectomy has been noted where, in the presence of pneumatisation of the articular eminence, there is an increased risk of intracranial spread of inflammation along with an increased risk of temporal bone fracture [17]. The presence of pneumatisation can be identified through radiographic examination with both orthopantomogram (OPT) and computed tomography (CT) [18].

The visual analogue scale and Wilkes staging system are established and accepted forms of grading for internal derangement of the TMJ $[11,12]$. The retrospective nature and geographical distribution of the study has led to these data being poorly recorded and its documentation would have further strongly supported this study. Current guidelines would be in conflict with this surgical procedure and would offer TMJ arthrocentesis as a first-line surgical treatment. The time frame over which the data have been collected and the large numbers make this study still an important contributor to the role of temporomandibular joint eminectomy as a second-line surgical option in selected cases, even in modern-day surgical management of refractory closed lock of TM joint.

This large, multi-centred retrospective study carried out at three different centres with consultant-led surgeries shows eminectomy to be a safe and reliable procedure in the treatment of closed lock. It shows statistically significant improvement in mouth opening (IID), where $\mathrm{p}$ was calculated to be $<0.05$, with a mean IID of $37 \mathrm{~mm}$ at discharge from the clinic, 6 months post-operatively. There was complete resolution of a click in $58 \%$ of the cases and along with reduction in subjective pain symptoms in 56\% cases leading to satisfactory discharge in 108 out of 164 cases.

Open Access This article is distributed under the terms of the Creative Commons Attribution 4.0 International License (http://crea tivecommons.org/licenses/by/4.0/), which permits unrestricted use, distribution, and reproduction in any medium, provided you give appropriate credit to the original author(s) and the source, provide a link to the Creative Commons license, and indicate if changes were made.

\section{References}

1. Durham J, Newton-John T, Zakrzewska JM (2015) Temporomandibular disorders. BMJ 350:h1154. https://doi.org/10.1136/ bmj.h1154

2. Rigon M, Pereira LM, Bortoluzzi MC, Loguercio AD, Ramos AL, Cardoso JR (2011) Arthroscopy for temporomandibular disorders. Cochrane Database Syst Rev 11(5):CD006385

3. Swift JQ, Roszkowski MT, Alton T, Hargreaves KM (1998) Effect of intra-articular versus systemic anti-inflammatory drugs in a rabbit model of temporomandibular joint inflammation. J Oral Maxillofac Surg 56(11):1288-1295

4. Al-Baghdadi M, Durham J, Araujo-Soares V, Robalino S, Errington L, Steele J (2014) TMJ Disc displacement without reduction management: a systematic review. J Dent Res 93(7 Suppl):37S-51S

5. Stassen LF, O'Halloran M (2011) Functional surgery of the temporomandibular joint with conscious sedation for "closed 
lock" using eminectomy as a treatment: a case series. J Oral Maxillofac Surg 69(6):e42-e49

6. Paegle DI, Holmlund A, Hjerpe A (2005) Expression of proteoglycan mRNA in patients with painful clicking and chronic closed lock of the temporomandibular joint. Int J Oral Maxillofac Surg 34:656-658

7. Schiffman EL, Velly AM, Look JO, Hodges JS, Swift JQ, Decker $\mathrm{KL}$ et al (2014) Effects of four treatment strategies for temporomandibular joint closed lock. Int J Oral Maxillofac Surg 43(2):217-226

8. Stassen LF, Currie WJR (1994) A pilot study of the use of eminectomy in the treatment of closed lock. Br J Oral Maxillofac Surg 32:138-141

9. Donlon WC, Moon KL (1984) Comparison of MRI, arthrotomography and clinical surgical findings in TMJ internal derangements. Oral Surg Oral Med Oral Pathol 64:2-5

10. Pogrel MA (1987) Articular eminectomy for recurrent dislocation. Br J Oral Maxillofac Surg 25:237-243

11. Tzanidakis K, Sidebottom AJ (2013) Outcomes of open temporomandibular joint surgery following failure to improve after arthroscopy: Is there an algorithm for success? Br J Oral Maxillofac Surg 51:818-821

12. Wilkes $\mathrm{CH}$ (1989) Internal derangements of the temporomandibular joint. Pathological variations. Arch Otolaryngol Head Neck Surg 115:469-477
13. Hall MB (1984) Meniscoplasty of the displaced TMJ meniscus without violating the inferior joint space. J Oral Maxillofac Surg 42:788-792

14. Dolwick MF (2007) Temporomandibular joint surgery for internal derangement. Dent Clin N Am 51:195-208

15. Williamson EH (1990) Interrelationship of internal derangements of the temporomandibular joint, headache, vertigo and tinnitus: a survey of 25 patients. Cranio 8(4):301-306

16. Rahman Z, Chand M, Breeze J, Stocker J (2018) Success rates and complications of eminectomies: a retrospective case series. Oral Surg 11:28-32

17. Miloglu O, Yilmaz AB, Yildirim E, Akgul HM (2011) Pneumatization of the articular eminence on cone beam computed tomography: prevalence, characteristics and a review of the literature. Dentomaxillofac Radiol 40:110-114

18. Vasconcelos BCE, Porto GG, Neto JPMR, Vasconcelos CFM (2009) Treatment of chronic mandibular dislocations by eminectomy: follow up of 10 cases and literature review. Med Oral Patol Oral Cir Bucal 14:593-596

Publisher's Note Springer Nature remains neutral with regard to jurisdictional claims in published maps and institutional affiliations. 